\title{
New Complex Isoflavones in the Roots of Yellow Lupin (Lupinus luteus L., cv. Barpine) $^{\dagger}$
}

\author{
Yasuyuki Hashidoko, Satoshi Tahara* and Junya Mizutani \\ Department of Agricultural Chemistry, Faculty of Agriculture, Hokkaido University, \\ Kita-ku, Sapporo 060, Japan \\ Received January 13, 1986
}

\begin{abstract}
Six new isoflavones each having a prenyl (3,3-dimethylallyl) or a modified prenyl group at C-6 or C-8 of the isoflavone skeleton, lupiwighteone [5,7,4'-trihydroxy-8-(3,3-dimethylallyl)isoflavone, 1], luteone hydrate [5,7,2',4'-tetrahydroxy-6-(3-hydroxy-3-methylbutyl)isoflavone, 3 (already known as a fungal metabolite of luteone)], lupiwighteone hydrate [5,7,4'-trihydroxy-8-(3-hydroxy3-methylbutyl)isoflavone, 4], 2,3-dehydrokievitone hydrate [5,7,2', $4^{\prime}$-tetrahydroxy-8-(3-hydroxy3-methylbutyl)isoflavone, 5], hydroxywighteone [5,7',4'-trihydroxy-6-(3-hydroxymethyl-3-methylallyl)isoflavone, 6], hydroxyparvisoflavone A [a 2-hydroxymethyl-2-methylpyrano-isoflavone, 7], and a new coumaronochromone, lupilutin [5,7,4'-trihydroxy-8-(3-hydroxy-3-methylbutyl)coumaronochromone, 8], were isolated from the roots of yellow lupin (Lupinus luteus L., cv. Barpine). Together with these new isoflavonoids, the presence of simple isoflavones (genistein and 2'-hydroxygenistein) and complex isoflavones (wighteone, luteone, 2,3-dehydrokievitone (2), parvisoflavones A and B, and lupinisoflavones A and B) in the yellow lupin roots has also been confirmed.
\end{abstract}

During a survey of antifungal isoflavones in lupins, the roots of white lupin (Lupinus albus) were found to contain numerous simple and complex isoflavones. ${ }^{1 \sim 3)}$ The latter isoflavones were revealed to possess one (at C-6 or C-3') or two (at C-6 and C-3') prenyl substituents, or those modified to a dihydrofuran or a pyran ring. The rare isoflavonoids, coumaronochromones (lupinalbins $\mathrm{A} \sim \mathrm{E}$ ) have also been isolated from white lupin roots.

However, we have recently found that the roots of yellow lupin, L. luteus L., cv. Barpine (Leguminosae), contained further isoflavonoids structurally different from those of white lupin in three respects: prenylation at C-8 in the A-ring of the isoflavone skeleton, hydroxylation or hydration of the prenyl substituent, and 5-O-methylation. This paper describes the isolation and structural elucidation of yellow lupin isoflavonoids except for 5-O-methyl derivatives.

The methanol extractives of $L$. luteus were initially fractionated into nine portions (Fr$1 \sim$ Fr-9) by silica gel column chromatography (CC, see Experimental for details of $\mathrm{CC}$ and TLC). The constituents in each fraction were subjected once more to $\mathrm{CC}$ over silica gel or Sephadex LH-20. The focused constituent in a column chromatography eluate thus obtained was further purified by repeated PTLC. New substances isolated from the yellow lupin roots by the present study were respectively designated BR-A $\sim \mathrm{BR}-\mathrm{H}$ as shown in Table I. These substances, except for BR-F, showed their UV methanolic maxima in the region of $265 \sim 269 \mathrm{~nm}$ and, furthermore, those on TLC plates fluoresced dark purple under $\mathrm{UV}_{365 \mathrm{~nm}}$ light. The former property is characteristic of the isoflavone skeleton ${ }^{4)}$ and the latter, of 5hydroxylated isoflavones. ${ }^{5)}$ The ${ }^{1} \mathrm{H}-\mathrm{NMR}$ spectrum of each substance (BR-A $\sim B R-E$, BR-G and BR-H) showed a heterocyclic olefin proton of isoflavone (C-2-H) as a sharp singlet in a low magnetic field $\left.(\delta 8.14 \sim 8.26) .{ }^{6}\right)$ Apart

+ Isoflavonoids of Yellow Lupin. Part I.

* To whom inquiries should be addressed. 
Table I. Some Properties of the Complex Isoflavones Isolated from Yellow Lupin Roots

\begin{tabular}{|c|c|c|c|c|c|c|c|c|c|c|c|}
\hline \multirow{2}{*}{ Code } & \multirow{2}{*}{ Compound $^{a}$} & \multirow{2}{*}{ MW } & \multirow{2}{*}{ Formula } & \multirow{2}{*}{$\begin{array}{l}\text { Gibbs test } \\
\text { (Rate) }\end{array}$} & \multirow{2}{*}{ Fluorescence $^{b}$} & \multicolumn{3}{|c|}{$\mathrm{UV} \lambda_{\max }(\mathrm{nm})$} & \multicolumn{3}{|c|}{$R f^{c} \times 100$} \\
\hline & & & & & & $\mathrm{MeOH}$ & $+\mathrm{AlCl}_{3}$ & $+\mathrm{NaOAc}$ & $\mathrm{CM}$ & CAAm & PEAa \\
\hline BR-A & 2,3-Dehydrokievitone (2) & 354 & $\mathrm{C}_{20} \mathrm{H}_{18} \mathrm{O}_{6}$ & $+($ Rapid $)$ & Dark purple & 265 & 275 & 279 & 24 & 49 & 11 \\
\hline BR-B & Lupiwighteone (1) & 338 & $\mathrm{C}_{20} \mathrm{H}_{18} \mathrm{O}_{5}$ & - & Dark purple & 266 & 279 & 269 & 34 & 64 & 20 \\
\hline BR-C & Luteone hydrate (3) & 372 & $\mathrm{C}_{20} \mathrm{H}_{20} \mathrm{O}_{7}$ & $+($ Rapid $)$ & Dark purple & 266 & 275 & $272 \sim 278$ br & 13 & 16 & 2 \\
\hline BR-D & 2,3-Dehydrokievitone hydrate (5) & 372 & $\mathrm{C}_{20} \mathrm{H}_{20} \mathrm{O}_{7}$ & $+($ Rapid $)$ & Dark purple & 265 & 274 & 269 & 13 & 14 & 2 \\
\hline BR-E & Lupiwighteone hydrate (4) & 356 & $\mathrm{C}_{20} \mathrm{H}_{20} \mathrm{O}_{6}$ & - & Dark purple & 266 & 278 & 269 & 18 & 22 & 3 \\
\hline BR-F & Lupilutin (8) & 370 & $\mathrm{C}_{20} \mathrm{H}_{18} \mathrm{O}_{7}$ & - & Brownish yellow & 258 & 272 & $258 \mathrm{br}$ & 14 & 18 & 5 \\
\hline BR-G & Hydroxywighteone (6) & 354 & $\mathrm{C}_{20} \mathrm{H}_{18} \mathrm{O}_{6}$ & + (Slow) & Dark purple & 267 & 271 & 270 & 21 & 30 & 3 \\
\hline BR-H & Hydroxyparvisoflavone A (7) & 368 & $\mathrm{C}_{20} \mathrm{H}_{16} \mathrm{O}_{7}$ & $+($ Rapid $)$ & Dark purple & 269 & $279 \sim 285$ & $269 \sim 272$ br & 19 & 38 & 3 \\
\hline
\end{tabular}

a Structures are shown in Fig. 1.

$b$ Viewed under $\mathrm{UV}_{365 \mathrm{~nm}}$ light.

c TLC solvent systems are given in EXPERIMENTAL. 
from the isolates already mentioned, BR-F showed a slightly different UV absorption pattern and a brownish yellow fluorescence under $\mathrm{UV}_{365 \mathrm{~nm}}$ light, while the $\mathrm{C}-2$ proton characteristic of an isoflavone skeleton was not detected in the ${ }^{1} \mathrm{H}-\mathrm{NMR}$ spectrum. These facts were effective enough clues to consider a close relationship between BR-F and lupinalbins $\mathrm{A} \sim \mathrm{E}$ previously isolated as a series of coumaronochromones from white lupin roots. ${ }^{3)}$

BR-A was isolated from fractions FFr-406 and FFr-407 of the 2nd CC of Fr-4 over Sephadex LH-20 by PTLC and crystallization in acetone/hexane. In the MS spectrum, the molecular ion was detected at $\mathrm{m} / z \quad 354$ $\left(\mathrm{C}_{20} \mathrm{H}_{18} \mathrm{O}_{6}\right)$ with intense fragments at $m / z 311$ $\left(\mathbf{M}^{+}-43\right)$ and $299\left(\mathbf{M}^{+}-55\right)(\mathbf{b}$ and $\mathbf{d}$ in Fig. 2 , respectively), which are characteristic of prenylated isoflavones ( $c f$. luteone, wighteone and licoisoflavone $\mathrm{A}^{1,2)}$ ). Significantly, the mass fragmentation lost parts of the prenyl sidechain followed by retro-Diels-Alder (RDA) fission to give fragments at $m / z 165$ (e) and $134(\mathbf{g}) \cdot{ }^{6)}$ As the UV methanolic $\lambda_{\max }$ at $265 \mathrm{~nm}$ of BR-A was shifted bathochromically by $10 \sim 14 \mathrm{~nm}$ upon the addition of $\mathrm{AlCl}_{3}$ or $\mathrm{NaOAc}$, the A-ring of this isoflavone must have been hydroxylated at both C-5 and C-7.4) Together with a hydrogen-bonded C-5-OH resonating at $\delta 12.70$ and an isoflavone heterocyclic C-2 proton at $\delta 8.26$, the ${ }^{1} \mathrm{H}-\mathrm{NMR}$ of BR-A gave two sets of proton signals attributable to a prenyl group $[\delta 1.66$ and 1.81 (each $3 \mathrm{H}$, two s), $3.46(2 \mathrm{H}$, br. d, $J=7.1 \mathrm{~Hz})$ and 5.26 $(1 \mathrm{H}$, br. t, $J=7.1 \mathrm{~Hz})]$, and to a $2^{\prime}, 4^{\prime}$-dihydroxylated B-ring [an ABX system: $6.44(1 \mathrm{H}$, $\left.\mathrm{dd}, J \mathrm{H}_{\mathrm{AB}}=1.7, J \mathrm{H}_{\mathrm{AX}}=8.6 \mathrm{~Hz}, 5-\mathrm{H}_{\mathrm{A}}\right), 6.49$ $\left(1 \mathrm{H}\right.$, incomplete $\left.\mathrm{d}, 3-\mathrm{H}_{\mathrm{B}}\right)$ and $7.18(1 \mathrm{H}, \mathrm{d}, J$ $\mathrm{H}_{\mathrm{AX}}=8.6 \mathrm{~Hz}, 6-\mathrm{H}_{\mathrm{X}}$ ), respectively (Table II). The remaining aromatic proton observed at $\delta 6.39$ as a singlet, therefore, must be assigned to $\mathrm{C}-6-\mathrm{H}$, because $\mathrm{C}-8-\mathrm{H}$ of 9 having a 5,7dihydroxy-6-prenyl A-ring resonated quite differently at $\delta 6.53$. BR-A can thus be represented by structure 2 (Fig. 1), consisting of a 5,7dihydroxy-8-prenyl A-ring and a 2',4'-dihydroxylated B-ring. 2,3-Dehydrokievitone, a phytoalexin isolated from Phaseorus aureus inoculated with Monilinia fructicola, has also been formulated as $2{ }^{7)}$ and a spectroscopic (UV, MS, ${ }^{1} \mathrm{H}-\mathrm{NMR}$ ) comparison with BR-A confirmed that the two compounds were indeed identical. This is, however, the first isolation of an 8-prenylated isoflavone from Lupinus plants.

The whole structure of BR-B, depicted as $\mathbf{1}$ in Fig. 1, immediately became feasible, on the basis of the MS $\left[\mathrm{M}^{+} 338\left(\mathrm{C}_{20} \mathrm{H}_{18} \mathrm{O}_{5}\right)\right.$; fragments $m / z 323\left(\mathbf{M}^{+}-15\right), 283\left(\mathbf{M}^{+}-55, \mathbf{c}\right)$ and $270\left(\mathrm{M}^{+}-68\right.$, arising from fission at a prenyl sidechain); $m / z 165$ (e) and 118 (f, from RDA fission)] and ${ }^{1} \mathrm{H}-\mathrm{NMR}[\delta 6.90$ and 7.46 (both $2 \mathrm{H}$, two br. d, $J=8.7 \mathrm{~Hz}$ ) characteristic of 4'-hydroxylated B-ring protons, and a singlet at $\delta 6.37$ assignable to an A-ring proton not at C-8 (in the case of 10, $\delta 6.49$ ) but at C-6]. The structural and consequently spectroscopic relationship between BR-B (1) and its regioisomer (10) well resembled those of BR-A (2) and luteone (9) (Fig. 1 and Table II). Other properties of BR-B (1), for example, the bathochromic shift of the methanolic UV maximum with $\mathrm{AlCl}_{3}(\mathrm{C}-5-\mathrm{OH})$ or NaOAc $(\mathrm{C}$ 7-OH $){ }^{4}{ }^{4}$ and the negative response to Gibbs reagent (colored grey/yellow), are also well explained with the proposed structure. BR-B thus elucidated as 5,7,4'-trihydroxy-8-(3,3-dimethylallyl)isoflavone was a naturally occurring new isoflavone, and we propose to name it lupiwighteone.

BR-C and BR-D were obtained as mixed crystals. By multiple-development $(\times 5 \sim 6)$ PTLC in CM (50:3), the mixture was divided into two bands (upper one, BR-C and lower, BR-D). Each isolate gave the molecular ion at $\mathrm{m} / \mathrm{z} 372$ (luteone (9) or 2,3-dehydrokievitone (2) +18 mass units) and intense mass fragments at $m / z 354\left(\mathrm{M}^{+}-\mathrm{H}_{2} \mathrm{O}\right), 311\left(\mathrm{M}^{+}-\right.$ $\left.\mathrm{H}_{2} \mathrm{O}-43\right), 299\left(\mathrm{M}^{+}-\mathrm{H}_{2} \mathrm{O}-55\right), 165$ (e) and 134 (g), which seem to have been derived by the initial loss of $\mathrm{H}_{2} \mathrm{O}$ from the molecular ion that preceded alk(en)yl fissions at the sidechain and RAD fission at the heterocyclic ring, as with luteone hydrate (3), ${ }^{8)}$ or wighteone hydrate $(\mathbf{1 3})^{9)}$ that was formerly obtained as a fungal metabolite of 9 or wighteone (10). The 


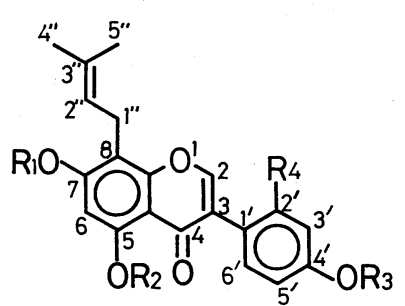

$\mathrm{R}_{1}=\mathrm{R}_{2}=\mathrm{R}_{3}=\mathrm{R}_{4}=\mathrm{H}$ lupiwighteone (1)

$\mathrm{R}_{1}=\mathrm{R}_{2}=\mathrm{R}_{3}=\mathrm{Ac} \mathrm{R}_{4}=\mathrm{H}$

$\mathrm{R}_{1}=\mathrm{R}_{2}=\mathrm{R}_{3}=\mathrm{H} \mathrm{R}_{4}=\mathrm{OH}$

$\mathrm{R}_{1}=\mathrm{R}_{2}=\mathrm{R}_{3}=\mathrm{Me} \mathrm{R}_{4}=\mathrm{OMe}$ $R_{1}=R_{2}=R_{3}=$ Ac $R_{4}=$ OAc lupiwighteone triacetate (1a)

2,3-dehydrokievitone (2)

2,3-dehydrokievitone tetramethylether (2a)

2,3-dehydrokievitone tetraacetate $(\mathbf{2 b})$

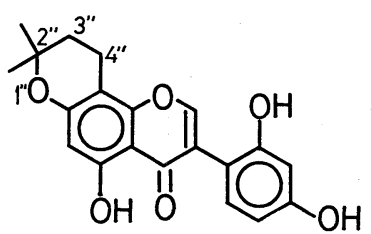

cyclo-2,3-dehydrokievitone (2c)<smiles>[R]c1cc(O)ccc1-c1coc2cc(O)c(CCC(C)(C)O)c(O)c2c1=O</smiles>

$\mathrm{R}=\mathrm{OH}$ luteone hydrate (3)

$\mathrm{R}=\mathrm{H} \quad$ wighteone hydrate (13)<smiles>[R1]CC(C)=CCc1c(O)cc2occ(-c3ccc(O)cc3[R2])c(=O)c2c1O</smiles>

$\mathrm{R}_{1}=\mathrm{OH} \mathrm{R}_{2}=\mathrm{H}$ hydroxywighteone (6)

$\mathrm{R}_{1}=\mathrm{H} \mathrm{R}_{2}=\mathrm{OH}$ luteone (9)

$\mathrm{R}_{1}=\mathrm{R}_{2}=\mathrm{H}$ wighteone (10)

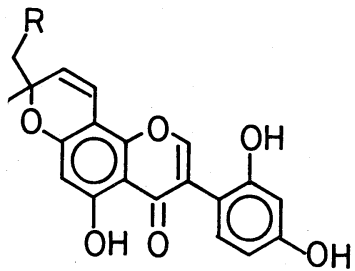

$\mathrm{R}=\mathrm{OH}$ hydroxyparvisoflavone $\mathrm{A}$ (7)

$\mathrm{R}=\mathrm{H}$ parvisoflavone $\mathrm{A}(\mathbf{1 1})$<smiles>CC1(C)C=Cc2c(cc3occ(-c4ccc(O)cc4O)c(=O)c3c2O)O1</smiles>

parvisoflavone B (12)

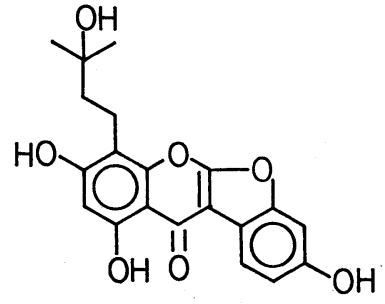

lupilutin (8)

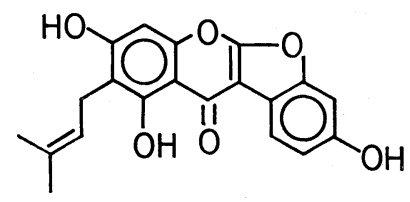

lupinalbin B (14)

FIG. 1. Structures of the Complex Isoflavones Isolated from Yellow Lupin Roots and of Related Compounds.

$\mathrm{UV} \lambda_{\max }^{\mathrm{MeOH}}$ of each isolate invariably underwent a bathochromic shift with NaOAc (C-7$\mathrm{OH})$ or $\mathrm{AlCl}_{3}(\mathrm{C}-5-\mathrm{OH}) .{ }^{4)}$ As given in Table II, $\mathrm{BR}-\mathrm{C}$ and $\mathrm{BR}-\mathrm{D}$ respectively contained three B-ring protons showing an ABX-coupling system as with those of $\mathbf{9}$, as well as a set of proton signals [BR-C: at $\delta 1.25\left(6 \mathrm{H}, \mathrm{s}, \mathrm{H}_{3} \times 2\right)$, $1.71(2 \mathrm{H}, \mathrm{m})$ and $2.81(2 \mathrm{H}, \mathrm{m})$; BR-D: at $\delta 1.25$ $\left(6 \mathrm{H}, \mathrm{s}, \mathrm{H}_{3} \times 2\right), 1.73(2 \mathrm{H}, \mathrm{m})$ and $\left.2.87(2 \mathrm{H}, \mathrm{m})\right]$ assignable to protons of a 3-hydroxy-3-methylbutyl sidechain. ${ }^{8,9)}$ The distinctive feature of ${ }^{1} \mathrm{H}-\mathrm{NMR}$ signals of these two isolates was 
TABle II. ${ }^{1}$ H-NMR Data for the Complex Isoflavones Isolated from Yellow Lupin Roots and for StRucturally Related Compounds Chemical shifts ( $\delta$ value) were obtained in acetone- $d_{6}$ (TMS reference) at either $100 \mathrm{MHz}$ or $400 \mathrm{MHz}$.

\begin{tabular}{|c|c|c|c|c|c|c|c|c|c|c|c|c|}
\hline Isoflavone & $6-\mathrm{H}$ & 8-H & $2-\mathrm{H}$ & $5-\mathrm{OH}$ & $2^{\prime}-\mathrm{H}$ & $6^{\prime}-\mathrm{H}$ & $3^{\prime}-\mathrm{H}$ & $5^{\prime}-\mathrm{H}$ & $1^{\prime \prime}-\mathrm{H}$ & $2^{\prime \prime}-\mathrm{H}$ & $4^{\prime \prime}-\mathrm{H}_{3}$ & $5^{\prime \prime}-\mathrm{H}_{3}$ \\
\hline Luteone (9) & - & $6.53 \mathrm{~s}$ & $8.14 \mathrm{~s}$ & $13.05 \mathrm{~s}$ & - & $\begin{array}{l}7.12 \mathrm{~d} \\
(8.9)\end{array}$ & $\begin{array}{c}6.48 \mathrm{~d} \\
\text { (Imcomplete) }\end{array}$ & $\begin{array}{c}6.44 \mathrm{dd} \\
(8.9 \& 2.4)\end{array}$ & $\begin{array}{l}3.37 \text { br. d } \\
(7.3)\end{array}$ & $\begin{array}{l}5.28 \text { br. } \mathrm{t} \\
(\text { ca. } 7)\end{array}$ & $1.65 \mathrm{~s}$ & $1.78 \mathrm{~s}$ \\
\hline Luteone hydrate (3) & - & $6.51 \mathrm{~s}$ & $8.14 \mathrm{~s}$ & $13.04 \mathrm{~s}$ & - & $\begin{array}{l}7.12 \mathrm{~d} \\
(8.8)\end{array}$ & $\begin{array}{c}6.48 \mathrm{~d} \\
\text { (Incomplete) }\end{array}$ & $\begin{array}{l}6.43 \mathrm{dd} \\
(8.8 \& 2.4)\end{array}$ & $2.81 \mathrm{~m}$ & $1.71 \mathrm{~m}$ & \multicolumn{2}{|c|}{$\begin{array}{r}1.25 \mathrm{~s} \\
{[6 \mathrm{H}]}\end{array}$} \\
\hline 2,3-Dehydrokievitone (2) & $6.39 \mathrm{~s}$ & - & $8.26 \mathrm{~s}$ & $12.70 \mathrm{~s}$ & - & $\begin{array}{l}7.18 \mathrm{~d} \\
(8.6)\end{array}$ & $\begin{array}{c}6.49 \mathrm{~d} \\
\text { (Incomplete) }\end{array}$ & $\begin{array}{c}6.44 \mathrm{dd} \\
(8.6 \& 1.7)\end{array}$ & $\begin{array}{l}3.46 \text { br. d } \\
\quad(7.1)\end{array}$ & $\begin{array}{l}5.26 \mathrm{br} . \mathrm{t} \\
(7.1)\end{array}$ & $1.66 \mathrm{~s}$ & $1.81 \mathrm{~s}$ \\
\hline $\begin{array}{r}\text { 2,3-Dehydrokievitone } \\
\text { hydrate (5) }\end{array}$ & $6.37 \mathrm{~s}$ & - & $8.26 \mathrm{~s}$ & $12.68 \mathrm{~s}$ & - & $\begin{array}{l}7.15 \mathrm{~d} \\
(8.5)\end{array}$ & $\begin{array}{c}6.49 \mathrm{~d} \\
\text { (Incomplete) }\end{array}$ & $\begin{array}{c}6.44 \mathrm{dd} \\
(8.5 \& 2.2)\end{array}$ & $2.87 \mathrm{~m}$ & $1.73 \mathrm{~m}$ & \multicolumn{2}{|c|}{$\begin{array}{r}1.25 \mathrm{~s} \\
{[6 \mathrm{H}]}\end{array}$} \\
\hline Wighteone (10) & - & $6.49 \mathrm{~s}$ & $8.15 \mathrm{~s}$ & $13.32 \mathrm{~s}$ & & $\begin{array}{l}7.46 \text { br. d } \\
(8.7)[2 \mathrm{H}]\end{array}$ & \multicolumn{2}{|c|}{$\begin{array}{l}6.90 \text { br.d } \\
(8.7)[2 \mathrm{H}]\end{array}$} & $\begin{array}{l}3.37 \text { br. d } \\
\quad(7.1)\end{array}$ & $\begin{array}{l}5.28 \text { br. } \mathrm{t} \\
(7.1)\end{array}$ & $1.65 \mathrm{~s}$ & $1.78 \mathrm{~s}$ \\
\hline Wighteone hydrate (13) & - & $6.47 \mathrm{~s}$ & $8.14 \mathrm{~s}$ & $13.31 \mathrm{~s}$ & & $\begin{array}{l}7.45 \text { br. d } \\
(8.8)[2 \mathrm{H}]\end{array}$ & \multicolumn{2}{|c|}{$\begin{array}{l}6.91 \text { br. d } \\
(8.8)[2 \mathrm{H}]\end{array}$} & $2.78 \mathrm{~m}$ & $1.71 \mathrm{~m}$ & \multicolumn{2}{|c|}{$\begin{array}{r}1.26 \mathrm{~s} \\
{[6 \mathrm{H}]}\end{array}$} \\
\hline Hydroxy wighteone (6) & - & $6.50 \mathrm{~s}$ & $8.15 \mathrm{~s}$ & $13.33 \mathrm{~s}$ & & $\begin{array}{l}7.46 \text { br. d } \\
(8.8)[2 \mathrm{H}]\end{array}$ & \multicolumn{2}{|c|}{$\begin{array}{l}6.90 \text { br. d } \\
(8.8)[2 \mathrm{H}]\end{array}$} & $\begin{array}{l}3.42 \text { br. d } \\
(7.6)\end{array}$ & $\begin{array}{l}5.52 \text { br. } \mathrm{t} \\
(7.6)\end{array}$ & $\begin{array}{c}3.90 \mathrm{br} . \mathrm{s} \\
{[2 \mathrm{H}]}\end{array}$ & $1.80 \mathrm{~s}$ \\
\hline Lupiwighteone (1) & $6.37 \mathrm{~s}$ & - & $8.26 \mathrm{~s}$ & $12.98 \mathrm{~s}$ & & $\begin{array}{l}7.46 \text { br. d } \\
(8.7)[2 \mathrm{H}]\end{array}$ & \multicolumn{2}{|c|}{$\begin{array}{l}6.90 \mathrm{br} \cdot \mathrm{d} \\
(8.7)[2 \mathrm{H}]\end{array}$} & $\begin{array}{l}3.45 \text { br. } d \\
\quad(7.3)\end{array}$ & $\begin{array}{l}5.25 \text { br. } \mathrm{t} \\
(7.3)\end{array}$ & $1.66 \mathrm{~s}$ & $1.81 \mathrm{~s}$ \\
\hline Lupiwighteone hydrate (4) & $6.34 \mathrm{~s}$ & - & $8.26 \mathrm{~s}$ & $12.97 \mathrm{~s}$ & & $\begin{array}{l}7.48 \text { br. d } \\
(8.8)[2 \mathrm{H}]\end{array}$ & \multicolumn{2}{|c|}{$\begin{array}{l}6.90 \text { br. d } \\
(8.8)[2 \mathrm{H}]\end{array}$} & ca. $2.85 \mathrm{~m}$ & $1.75 \mathrm{~m}$ & \multicolumn{2}{|c|}{$\begin{array}{r}1.27 \mathrm{~s} \\
{[6 \mathrm{H}]}\end{array}$} \\
\hline Parvisoflavone B (12) & - & $6.41 \mathrm{~s}$ & $8.17 \mathrm{~s}$ & $13.22 \mathrm{~s}$ & - & $\begin{array}{l}7.13 \mathrm{~d} \\
(8.3)\end{array}$ & $\begin{array}{c}6.49 \mathrm{~d} \\
\text { (Incomplete) }\end{array}$ & $\begin{array}{c}6.45 \mathrm{dd} \\
(8.3 \& 2.4)\end{array}$ & & & & \\
\hline Parvisoflavone A (11) & $6.22 \mathrm{~s}$ & - & $8.23 \mathrm{~s}$ & $12.92 \mathrm{~s}$ & - & $\begin{array}{l}7.13 \mathrm{~d} \\
(8.5)\end{array}$ & $\begin{array}{c}6.49 \mathrm{~d} \\
\text { (Incomplete) }\end{array}$ & $\begin{array}{c}6.45 \mathrm{dd} \\
(8.5 \& 2.2)\end{array}$ & & & & \\
\hline $\begin{array}{l}\text { Hydroxypar- } \\
\quad \text { visoflavone A (7) }\end{array}$ & $6.21 \mathrm{br} . \mathrm{s}$ & - & $8.23 \mathrm{~s}$ & $12.90 \mathrm{~s}$ & - & $\begin{array}{l}7.14 \mathrm{~d} \\
(7.8)\end{array}$ & $\begin{array}{c}6.49 \mathrm{~d} \\
\text { (Incomplete) }\end{array}$ & $\begin{array}{c}6.45 \mathrm{dd} \\
(7.8 \& 2.2)\end{array}$ & & & & \\
\hline Lupinalbin B (14) & - & $6.66 \mathrm{~s}$ & - & $13.27 \mathrm{~s}$ & - & $\begin{array}{l}7.82 \mathrm{~d} \\
(8.3)\end{array}$ & $\begin{array}{l}7.12 \mathrm{~d} \\
(1.9)\end{array}$ & $\begin{array}{c}7.02 \mathrm{dd} \\
(8.3 \& 1.9)\end{array}$ & $\begin{array}{l}3.39 \text { br. } d \\
(7.6)\end{array}$ & $\begin{array}{l}5.29 \text { br. } \mathrm{t} \\
(\text { ca. } 7)\end{array}$ & $1.66 \mathrm{~s}$ & $1.80 \mathrm{~s}$ \\
\hline Lupilutin (8) & $6.42 \mathrm{~s}$ & - & - & $12.93 \mathrm{~s}$ & - & $\begin{array}{l}7.82 \mathrm{~d} \\
(8.3)\end{array}$ & $\begin{array}{l}7.15 \mathrm{~d} \\
(2.3)\end{array}$ & $\begin{array}{c}7.03 \mathrm{dd} \\
(8.3 \& 2.3)\end{array}$ & $2.87 \mathrm{~m}$ & $1.78 \mathrm{~m}$ & $\begin{array}{r}1.3 \\
{[\epsilon}\end{array}$ & \\
\hline
\end{tabular}

$a$ Pyran ring protons for parvisoflavone B: $\delta 5.79\left(1 \mathrm{H}, \mathrm{d}, J=10.0 \mathrm{~Hz}, 3^{\prime \prime}-\mathrm{H}\right), 6.69\left(1 \mathrm{H}, \mathrm{d}, J=10.0 \mathrm{~Hz}, 4^{\prime \prime}-\mathrm{H}\right)$ and $1.48\left(6 \mathrm{H}, \mathrm{s}, 2 \times 22^{\prime \prime}-\mathrm{CH}\right)$; for parvisoflavone A: $\delta 5.76(1 \mathrm{H}$, $\left.\mathrm{d}, J=10.0 \mathrm{~Hz}, 3^{\prime \prime}-\mathrm{H}\right), 6.74\left(1 \mathrm{H}, \mathrm{d}, J=10.0 \mathrm{~Hz}, 4^{\prime \prime}-\mathrm{H}\right)$ and $1.48\left(6 \mathrm{H}, \mathrm{s}, 2 \times 2^{\prime \prime}-\mathrm{CH}_{3}\right)$; and for hydroxyparvisoflavone $\mathrm{A}: \delta 5.74\left(1 \mathrm{H}, \mathrm{d}, J=10.3 \mathrm{~Hz}, 3^{\prime \prime}-\mathrm{H}\right), 6.81(1 \mathrm{H}, \mathrm{d}$, $\left.J=10.3 \mathrm{~Hz}, 4^{\prime \prime}-\mathrm{H}\right), 3.68\left(2 \mathrm{H}\right.$, br. s, $\left.2^{\prime \prime}-\mathrm{CH}_{2} \mathrm{OH}\right)$, and $1.43\left(3 \mathrm{H}, \mathrm{s}, 2^{\prime \prime}-\mathrm{CH}_{3}\right)$. 
found only in the chemical shift values of their A-ring protons. These two isolates were therefore revealed to be isomeric with each other regarding the position of the sidechain (both alkylated on the A-ring, one at C-6 and the other at C-8). Direct spectroscopic (UV, MS, and ${ }^{1} \mathrm{H}-\mathrm{NMR}$ ) and chromatographic (silica gel TLC) comparisons between luteone hydrate ${ }^{8)}$ and BR-C confirmed that the two compounds were indeed identical. BR-D was consequently revealed to be 5,7,2',4'-tetrahydroxy-8-(3-hydroxy-3-methylbutyl)isoflavone (5), which we propose to name 2,3-dehydrokievitone hydrate. The chemical shift value for the C-8 proton of 9 or the C-6 proton of 2 was hardly affected (shifted to a higher field by only
$0.02 \mathrm{ppm}$, Table II) by hydration at the prenyl sidechain.

The structure of BR-E was immediately deduced to be a hydrate of lupiwighteone (1), because of the following evidence indicative of the presence of a 4'-hydroxylated B-ring [mass fragment at $m / z 118$ (f) and ${ }^{1} \mathrm{H}-\mathrm{NMR}$ detection of four aromatic protons similarly resonating as those of 1 (Table II)] and the presence of a 5,7-dihydroxy-8-(3-hydroxy-3-methylbutyl)A-ring [mass fragments at $m / z 338$ $\left(\mathrm{M}^{+}-\mathrm{H}_{2} \mathrm{O}\right), 295\left(\mathrm{M}^{+}-\mathrm{H}_{2} \mathrm{O}-43\right), 283\left(\mathrm{M}^{+}\right.$ $\left.-\mathrm{H}_{2} \mathrm{O}-55\right)$ and $\left.165(\mathrm{e})\right]$, a set of ${ }^{1} \mathrm{H}-\mathrm{NMR}$ proton signals attributable to 3-hydroxy-3methylbutyl partial structure [1.27 $(6 \mathrm{H}, \mathrm{s}), 1.75$ $(2 \mathrm{H}, \mathrm{m})$ and $c a .2 .85(2 \mathrm{H}, \mathrm{m})]$, and an aromatic

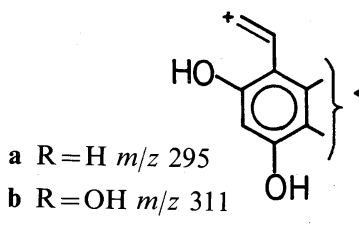

$-43$
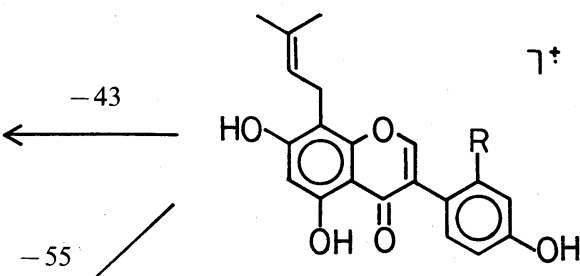

$\mathrm{R}=\mathrm{H} m / z 338$

$\mathrm{R}=\mathrm{OH} m / z 354$

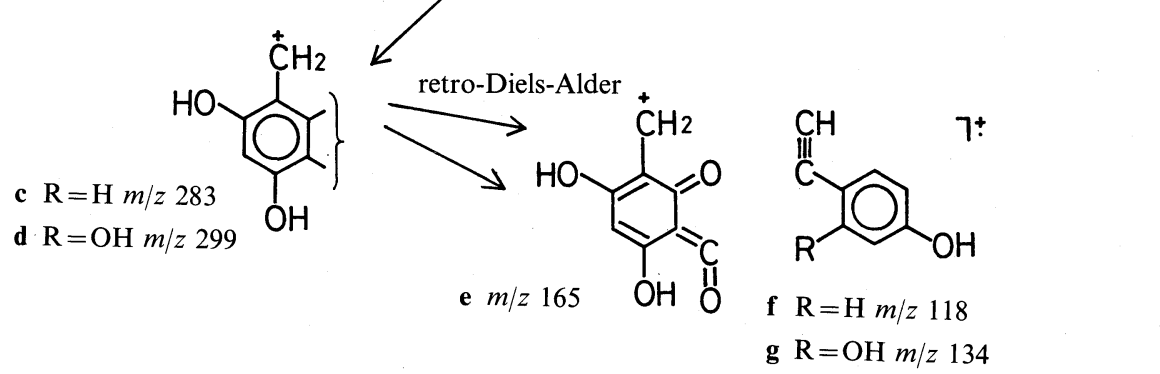

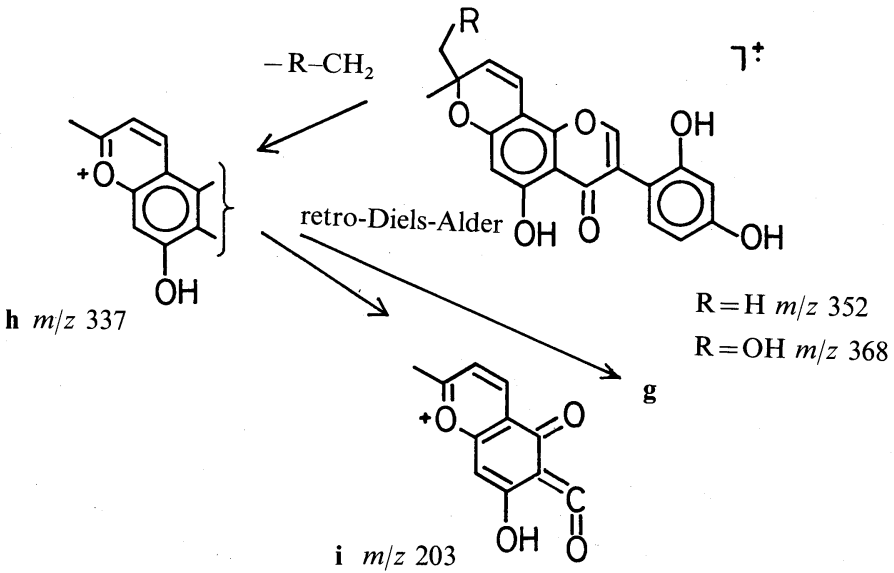

FIG. 2. Mass Fragments Mentioned in the Text. 
proton of the A-ring at $\delta 6.34$ (s) assignable not to the C- 8 proton but to the C- 6 proton. As shown in our earlier paper, ${ }^{9)}$ the $\mathrm{C}-8-\mathrm{H}$ of wighteone hydrate (13) was quite differently observed at $\delta 6.47$ under the same conditions. BR-E was thus confirmed to be 5,7,4'-trihydroxy-8-(3-hydroxy-3-methylbutyl)isoflavone (4) and is named lupiwighteone hydrate.

A new coumaronochromone (BR-F) was isolated as colorless columns. The coumestan structure (isomeric with the coumaronochromone skeleton) for BR-F was discounted for two reasons. Firstly, BR-F contained an Hbonded $\mathrm{OH}$ group as shown by the ${ }^{1} \mathrm{H}-\mathrm{NMR}$ signal at $\delta 12.93$ and the $\mathrm{AlCl}_{3}$-induced bathochromic shift of the UV $\lambda_{\max }^{\mathrm{MeOH}}$ at $258 \mathrm{~nm}$. Secondly, the carbonyl absorption in the IR spectrum of BR-F appeared at $1650 \mathrm{~cm}^{-1}$ (coumestan derivatives, $1730 \sim 1700 \mathrm{~cm}^{-110)}$ ). The UV spectral data for BR-F in $\mathrm{MeOH}$ with or without a shift reagent are shown in Table III in association with those of the lupin coumaronochromone, lupinalbin B (14). The isolated BR-F gave the molecular ion at $\mathrm{m} / z$ 370 and mass fragments at $\mathrm{m} / z \quad 352$ $\left(\mathrm{M}^{+}-\mathrm{H}_{2} \mathrm{O}\right), 309\left(\mathrm{M}^{+}-\mathrm{H}_{2} \mathrm{O}-43\right)$ and 297 $\left(\mathrm{M}^{+}-\mathrm{H}_{2} \mathrm{O}-55\right)$, as with $\mathrm{BR}-\mathrm{C} \sim \mathrm{BR}-\mathrm{E}$ which each had a hydrated prenyl group, whilst RDA fragments characteristic of the isoflavone skeleton were predictably not detected, as with lupinalbins $\mathrm{A} \sim \mathrm{E}$. The presence of a hydrated prenyl sidechain was confirmed by ${ }^{1} \mathrm{H}-\mathrm{NMR}$ detection of aliphatic protone signals $[\delta 1.31$ $(6 \mathrm{H}, \mathrm{s}), 1.78(2 \mathrm{H}, \mathrm{m})$ and $2.87(2 \mathrm{H}, \mathrm{m})]$ attributable to a 3-hydroxy-3-methylbutyl group. As the B-ring protons of BR-F resonated quite similarly to those of lupinalbin $A$ or B (having a 4'-hydroxylated coumaronochromone B-ring), BR-F must have been alkylated at the A-ring (C-6 or C-8). The position of the alkyl sidechain was finally specified to be at C-8 from ${ }^{1} \mathrm{H}-\mathrm{NMR}$ evidence. As shown in our previous paper, ${ }^{3)}$ the deshielding effects of the coumaronochromone ring formation on C-6-H and $\mathrm{C}-8-\mathrm{H}$ in the structurally corresponding 2'-hydroxy-isoflavones were $0.01 \sim 0.05 \mathrm{ppm}$ and $0.10 \sim 0.14 \mathrm{ppm}$, respectively. Therefore, the C-6-H of the couma-
TABle III. UV ABsoRPtion DATA FOR BR-F (Lupilutin, 8) AND Lupinalbin B (14)

\begin{tabular}{|c|c|c|c|c|c|}
\hline \multicolumn{6}{|c|}{$\lambda_{\max } \mathrm{nm}$ (Relative intensity $\%$ ) } \\
\hline \multicolumn{2}{|c|}{$\mathrm{MeOH}$} & \multicolumn{2}{|c|}{$+\mathrm{AlCl}_{3}$} & \multicolumn{2}{|c|}{$+\mathrm{NaOAc}$} \\
\hline \multicolumn{6}{|c|}{ Lupilutin (8) } \\
\hline 258 & $(100)$ & 218 & $(74)$ & $258 \mathrm{br}$ & $(100)$ \\
\hline 284 & $(30)$ & 233 & $(70)$ & $273 \mathrm{sh}$ & ( 64) \\
\hline $303 \mathrm{sh}$ & $(18)$ & 272 & $(100)$ & $292 \mathrm{sh}$ & ( 46$)$ \\
\hline \multirow[t]{4}{*}{340} & ( 28) & 288 & ( 57) & 347 & $(41)$ \\
\hline & & $304 \mathrm{sh}$ & ( 33$)$ & & \\
\hline & & 325 & ( 21$)$ & & \\
\hline & & 388 & ( 39$)$ & & \\
\hline \multicolumn{6}{|c|}{ Lupinalbin B (14) } \\
\hline $243 \mathrm{sh}$ & $(58)$ & 217 & ( 69) & $259 \mathrm{br}$ & $(100)$ \\
\hline 260 & $(100)$ & 240 & $(74)$ & $293 \mathrm{sh}$ & ( 52$)$ \\
\hline 286.5 & ( 41$)$ & 271.5 & $(100)$ & 349 & ( 57$)$ \\
\hline $301 \mathrm{sh}$ & ( 24) & 289 & ( 64) & & \\
\hline \multirow[t]{3}{*}{337} & ( 29) & $302 \mathrm{sh}$ & ( 36$)$ & & \\
\hline & & 331 & ( 32$)$ & & \\
\hline & & 384 & $(45)$ & & \\
\hline
\end{tabular}

ronochromone derived from 2,3-dehydrokievitone hydrate $(5, \mathrm{C}-6-\mathrm{H} ; \delta 6.37)$ was expected to resonate at around $\delta 6.38 \sim 6.42$, which agreed well with the observed chemical shift value for the A-ring proton of BR-F ( $\delta 6.42)$, whilst the $\mathrm{C}-8-\mathrm{H}$ of the coumaronochromone derived from luteone hydrate $(3, \mathrm{C}-8-\mathrm{H} ; \delta 6.51)$ was calculated to resonate at around $\delta 6.61 \sim$ 6.65. BR-F was thus identified to be the new coumaronochromone, 5,7,4'-trihydroxy-8-(3hydroxy-3-methylbutyl)coumaronochromone (8), and is named lupilutin.

The further 5-OH isoflavones, BR-G and BR-H, which fluoresced dark purple when viewed under $\mathrm{UV}_{365 \mathrm{~nm}}$ light, were found as minor constituents in Fr-9. BR-G reacted slowly with Gibbs reagent to give a blue/ green wighteone-type color on TLC plates, and exhibited a bathochromic shift with $\mathrm{NaOAc}(\mathrm{C}-7-\mathrm{OH})$ or $\mathrm{AlCl}_{3}(\mathrm{C}-5-\mathrm{OH})$. BR-G gave the molecular ion at $m / z 354\left(\mathrm{C}_{20} \mathrm{H}_{18} \mathrm{O}_{6}\right)$, and mass fragments at $m / z 336,321,295$ and 283 , which indicated the presence of a hydroxylated sidechain causative of yielding dehydration and dealk(en)ylation mass fragments. The structure of the hydroxylated sidechain became feasible by ${ }^{1} \mathrm{H}-\mathrm{NMR}$ detection of aliphatic proton signals at $\delta 1.80(3 \mathrm{H}$, br. s, 
$\left.\mathrm{C}_{3}-\mathrm{C}=\right), 3.90\left(2 \mathrm{H}\right.$, br. s, $\left.-\mathrm{C}_{2}-\mathrm{OH}\right), 3.42$ $\left(2 \mathrm{H}\right.$, br. d, $\left.J=7.6 \mathrm{~Hz},=\mathrm{CH}-\mathrm{C}_{-}{ }_{2}\right)$ and 5.52 $\left(1 \mathrm{H}\right.$, br. $\left.\mathrm{t}, J=7.6 \mathrm{~Hz},=\mathrm{C} \underline{\mathrm{H}}-\mathrm{CH}_{2}-\right)$, attributable to a 3-hydroxymethyl-2-butenyl group. Chemical shift values for the ring protons (2-, $8-, 2^{\prime}-, 3^{\prime}-, 5^{\prime}-$ and $\left.6^{\prime}-\mathrm{H}\right)$ and $\mathrm{C}-5-\mathrm{OH}$ of BR-G were in good agreement with those given in acetone- $d_{6}$ by wighteone (10) (Table II). The possibility of alk(en)ylation at C-8 was ruled out by the fact that BR-G gave slowly but clearly a blue/green pigment with Gibbs reagent $(=\mathrm{a}$ free position para to a phenolic hydroxyl group $\left.{ }^{11)}\right)$. BR-G was thus identified to be [5,7,4'-trihydroxy-6-(3-hydroxymethyl-3methylallyl)isoflavone and is named hydroxywighteone (6). The geometry (cis or trans) at the sidechain double bond in BR-G remains unresolved.

The MS of the final isolate BR-H gave the molecular ion at $m / z 368$ (trihydroxy-pyranoisoflavone +16 mass units), and intense mass fragments at $m / z 337\left(\mathrm{M}^{+}-\mathrm{CH}_{2} \mathrm{OH}, \mathbf{h}\right)$ and 203 (an RDA fragment derived from the pyrano-A-ring, i). The UV $\lambda_{\text {max }}^{\mathrm{MeOH}}$ at $267 \sim$ $271 \mathrm{~nm}$ was bathochromically shifted by $\mathrm{AlCl}_{3}$ (C-5-OH), but not clearly by $\mathrm{NaOAc}$ (probably $\mathrm{C}-7-\mathrm{OH}$ blocked). The chemical shift values for the aromatic and heterocyclic ring protons and $\mathrm{C}-5-\mathrm{OH}$ agreed well with those of not parvisoflavone B (linear-type, 12) but parvisoflavone A (angular-type, 11), and the difference in structure between BR-H and $\mathbf{1 1}$ was attributed to their side-structures. The exact side-structure of BR-H was deduced to be 2-hydroxymethyl-2-methylpyran fused to the A-ring in the manner depicted as compound 7 in Fig. 1, on the basis of a ${ }^{1} \mathrm{H}-\mathrm{NMR}$ analysis of the aliphatic proton signals $[\delta 1.43$ $\left(3 \mathrm{H}, \mathrm{s}, \mathrm{CH}_{3}-\right), 3.68$ (2H, br. s, $\left.-\mathrm{CH}_{2}-\mathrm{OH}\right)$, $5.74(1 \mathrm{H}, \mathrm{d}, J=10.3 \mathrm{~Hz},-\mathrm{CH}=\mathrm{CH}$-aryl $)$ and $6.81(1 \mathrm{H}$, br. d, $J=10.3 \mathrm{~Hz},-\mathrm{CH}=\mathrm{C} \underline{\mathrm{H}}-\mathrm{aryl}$, probably coupled weakly with C-6-H)]. BR-H was thus identified to be $5,2^{\prime}, 4^{\prime}$-trihydroxy$2^{\prime \prime}$-hydroxymethyl-2"'-methylpyrano $\left[5^{\prime \prime}, 6^{\prime \prime}\right.$ : 7,8 ]isoflavone, and is named hydroxyparvisoflavone A (7). Nothing is yet known about the stereo-chemistry at $\mathrm{C}-2^{\prime \prime}$.

Another compound $\left(\mathrm{M}^{+} 352\right)$, which fluo- resced dark purple under $\mathrm{UV}_{365 \mathrm{~nm}}$ light, was detected in the earlier column fractions FFr304 and FFr-305. This compound was recognized as a 5-hydroxyisoflavone lacking a free $\mathrm{OH}$ at $\mathrm{C}-7$, after determining its $\mathrm{UV}\left(\lambda_{\max }^{\mathrm{MeOH}}\right.$ $269 \mathrm{~nm} ;+\mathrm{NaOAc}$, unchanged; $+\mathrm{AlCl}_{3}, 285$ $\mathrm{nm})$ and ${ }^{1} \mathrm{H}-\mathrm{NMR}(\delta 8.23, \mathrm{C}-2-\mathrm{H} ; 12.92, \mathrm{C}-5$ $\mathrm{OH})$ spectra. ${ }^{1} \mathrm{H}-\mathrm{NMR}$ detection of aliphatic protons $[\delta 1.48(6 \mathrm{H}, \mathrm{s}), 5.76(1 \mathrm{H}, \mathrm{d}, J=10.0$ $\mathrm{Hz})$ and $6.74(1 \mathrm{H}, \mathrm{d}, J=10.0 \mathrm{~Hz})]$ attributable to a dimethyl-pyrano attachment and $2^{\prime}, 4^{\prime}$ dihydroxylated B-ring protons $[\delta 6.45 \mathrm{dd}, 6.49$ $\mathrm{d}$ and $7.14 \mathrm{~d}(\mathrm{ech} 1 \mathrm{H})$ ] resonating similarly to those of luteone (9) revealed the isolate to be one of the parvisoflavones $\mathrm{A}$ and $\mathrm{B}$, which were first extracted as a mixture from trunk wood of Poecilanthe parviflora (Leguminosae) ${ }^{12)}$ and which can be easily differentiated from each other by the ${ }^{1} \mathrm{H}-\mathrm{NMR}$ shift value for the A-ring proton ( $\delta 6.14$ for C-6-H of parvisoflavone $\mathrm{A}$ and $\delta 6.48$ for $\mathrm{C}-8-\mathrm{H}$ of parvisoflavone $\mathrm{B}$ in $\mathrm{CDCl}_{3}$ ). Our own work has also revealed that parvisoflavone $\mathrm{B}$ occurs in roots of the white lupin (Lupinus albus), and its C-8 proton resonates at $\delta 6.41$ in acetone- $d_{6}$. As the A-ring aromatic proton was detected at $\delta 6.22$ in acetone- $d_{6}$, the yellow lupin isolate was confirmed to be parvisoflavone A (Table II).

The isoflavonoidal constituents in the yellow lupin roots (L. luteus) were thus characterized. These compounds seem to be biosynthesized from two simple isoflavones, genistein and 2'hydroxygenistein, followed by specific prenylation at C- 6 or C-8, and the induced prenyl group probably futher underwent some modification reactions; for example, a) hydration at the prenyl double bond resulting in hydrates of luteone, lupiwighteone and 2,3-dehydrokievitone, b) cyclization of the prenyl sidechain with the phenolic ortho hydroxyl group to afford pyrano- or dihydrofurano-isoflavones, parvisoflavones $\mathrm{A}$ and $\mathrm{B}$, and lupinisoflavones $\mathrm{A}$ and $\mathrm{B}, \mathrm{c}$ ) hydroxylation at the terminal $\mathrm{CH}_{3}$ in the side attachment to yield hydroxywighteone and hydroxyparvisoflavone $\mathrm{A}$, and $\mathrm{d}$ ) cyclization at C-2 and C-2'-OH to provide the coumaronochromones, lupinalbins $\mathrm{A}$ and $\mathrm{B}$, and lupilutin. Another group of 5-O-methyl- 
isoflavones was also found in these yellow lupin roots, details of which will be fully reported elsewhere. ${ }^{13)}$

\section{EXPERIMENTAL}

General procedures (e.g., preparation of derivatives, silica gel TLC, and UV, MS and ${ }^{1} \mathrm{H}-\mathrm{NMR}$ measurements) were undertaken using the equipment, reagents and conditions described in our earlier papers. ${ }^{2,3)}$ Melting points (mp) were determined by the micro-hot-plate method and are uncorrected. TLC (PTLC) solvent systems were as follows unless otherwise mentioned: $\mathrm{CM}\left(\mathrm{CHCl}_{3}\right.$ : $\mathrm{MeOH}=50: 3)$, CAAm $\left(\mathrm{CHCl}_{3}\right.$ : acetone : conc. ammonia water $=60: 70: 2$ ) and PEAa (pentane : diethyl ether : glacial acetic acid $=75: 25: 4$ ).

Extraction and isolation of the isoflavonoidal constituents. The chopped roots $(4.25 \mathrm{~kg}$ of fresh material) of yellow lupin (L. luteus L., cv. Barpine) were soaked in 20 liters of $90 \% \mathrm{MeOH}$ in an aqueous solution for 2 weeks before the $\mathrm{MeOH}$ was decanted. This extraction procedure was repeated three times. The combined $\mathrm{MeOH}$ extracts were concentrated to $c a .500 \mathrm{ml}$, and acidified ( $\mathrm{pH} 3.0$ ) with $\mathrm{HCl}$ and followed by shaking with EtOAc $(\times 6)$. The EtOAc layers were collected and successively washed with $5.0 \%$ aq. $\mathrm{NaHCO}_{3}$ and saturated aq. $\mathrm{NaCl}$. The organic layer was poured into a Wako-gel C-200 $(50 \mathrm{~g})$ column settled in benzene. The root isoflavones and other constituents were then washed out with $70 \%$ EtOAc in hexane $(500 \mathrm{ml})$, and EtOAc $(300 \mathrm{ml})$. The combined eluates were concentrated in vacuo to remove the solvent. The residue was mixed with $200 \mathrm{ml}$ of $90 \% \mathrm{MeOH}$ and then washed with hexane $(200 \mathrm{ml} \times 2)$ to defat. The combined hexane layers were reversely extracted once with $90 \% \mathrm{MeOH}$ and then discarded. The $\mathrm{MeOH}$ solutions were combined and concentrated to near dryness. The remaining material was diluted with EtOAc and the solubles were adsorbed onto silica gel powder. Following removal of the EtOAc in vacuo, the gel coated with root extract was transferred to a column of Wako-gel $(300 \mathrm{~g})$ settled in benzene. The root isoflavones were eluted either with benzene, benzene plus increasing amounts of EtOAc, or EtOAc alone. The eluates $(250 \mathrm{ml}$ each) were collected as follows: Fraction (Fr)-1, washing with $15 \%$ EtOAc in benzene $(500 \mathrm{ml})$, did not contain any isoflavonoid but chlorophylls; Fr-2, 20\% EtOAc in benzene, involved only flavone-like constituents; $\mathrm{Fr}-3,20 \%$ EtOAc in benzene, contained the known isoflavones, luteone (9), wighteone (10), parvisoflavone B (12), lupinisoflavone $\mathrm{A}$ and lupinalbin $\mathrm{A} ; \mathrm{Fr}-4,20 \%$ EtOAc in benzene, with the greatest amount of $\mathbf{9}$, genistein and lupinalbin A; Fr-5, 20\% EtOAc in benzene, 9, genistein, lupinalbin $\mathrm{A}$ and 2 -hydroxygenistein; $\mathrm{Fr}-6,30 \%$ EtOAc in benzene, 2'-hydroxygenistein; Fr-7, 30\% EtOAc in benzene, 2'-hydroxygenistein; Fr- $8,35 \%$ EtOAc in benzene, $2^{\prime}$-hydroxygenistein, lupinisoflavone $B$ and an unknown isoflavone-like substance; and Fr-9, EtOAc $(800 \mathrm{ml})$, many kinds of unknown polar isoflavonoids.

After removing the crystallized $9(c a .500 \mathrm{mg})$, the constituents $(750 \mathrm{mg}$ ) in Fr-4 were dissolved in $50 \mathrm{ml}$ of $30 \%$ EtOAc in benzene and charged onto Sephadex LH-20 $(150 \mathrm{~g})$ column settled in $30 \%$ EtOAc in benzene. The eluates were collected as follows: Fraction (FFr)-401, washing with $30 \%$ EtOAc in benzene $(150 \mathrm{ml})$; FFr- 402 , EtOAc alone $(150 \mathrm{ml})$; $\mathrm{FFr}-403,20 \% \mathrm{MeOH}$ in EtOAc; FFr-404, 40\% MeOH in EtOAc; FFr- $405,60 \% \mathrm{MeOH}$ in EtOAc; $\mathrm{FFr}-406,80 \% \mathrm{MeOH}$ in EtOAc, 9 and BR-A; and FFr-407, MeOH alone, 9 and BR-A (FFr-403 407, each $100 \mathrm{ml})$.

The constituents $(2.0 \mathrm{~g})$ in Fr-3 were rechromatographed as described for Fr-4. The collected fractions (each $100 \mathrm{ml}$ ), eluting solvents and constituents were as follows: FFr-301, washing with $30 \%$ EtOAc in benzene; FFr-302, EtOAc alone; FFr-303, 50\% MeOH in EtOAc; FFr-304, $75 \% \mathrm{MeOH}$ in EtOAc, parvisoflavone A (11); $\mathrm{FFr}-305$, $90 \% \mathrm{MeOH}$ in EtOAc, 11; FFr-306, $\mathrm{MeOH}$ alone, BR-B and 10. BR-A ( $c a .150 \mathrm{mg}$ ) in FFr-406 and FFr-407, and BR-B ( $c a .10 \mathrm{mg}$ ) in FFr-306 were isolated by repeated PTLC in CAAm and CM, respectively.

The constituents in Fr-9 (7.8g) were dissolved with a small amount of acetone and charged as previously described for the primary chromatography. The collected fractions (each $100 \mathrm{ml}$ ) and eluting solvents were as follows: $\mathrm{FFr}-901 \sim 902,10 \%$ EtOAc in benzene; $\mathrm{FFr}-903$ 905, 20\% EtOAc in benzene; FFr-906 908, 30\% EtOAc in benzene; FFr-909 911, 40\% EtOAc in benzene; FFr912 914, 50\% EtOAc in benzene; and FFr-915 917, $60 \%$ EtOAc in benzene. The constituents, BR-C ( $c a$. $10 \mathrm{mg}$ ) and BR-D ( $c a .10 \mathrm{mg}$ ), were isolated from the combined fractions of FFr-916 and FFr-917 by multipledevelopment PTLC in CM and followed by PTLC in CAAm. BR-E ( $c a .5 \mathrm{mg}$ ), BR-F ( $c a .3 \mathrm{mg})$, BR-G ( $c a$. $4 \mathrm{mg})$ and BR-H ( $c a .2 \mathrm{mg}$ ) were isolated from the combined fractions of FFr-913 and FFr-914 by repeated PTLC in CAAm and CM $(50: 4)$ (see the $R f$ values in Table I).

Properties of the isolates and their chemical transformation products. Each known compound also isolated in the present study, genistein, 2'-hydroxygenistein, luteone, wighteone, ${ }^{1)}$ parvisoflavones $\mathrm{A}$ and $\mathrm{B},{ }^{2,12)}$ lupinisoflavones $\mathrm{A}$ and $\mathrm{B},{ }^{2)}$ lupinalbin $\mathrm{A}$ or lupinalbin $\mathrm{B},{ }^{3)}$ was identified by a direct comparison of its physicochemical properties with those of an authentic compound. Conversion (acetylation, methylation and acid-catalyzed cyclization of the prenyl group) were carried out as previously described. ${ }^{2}{ }^{1} \mathrm{H}$ NMR data for the isolates are given in Table II.

Lupiwighteone [BR-B, 1]. A pale yellow gum. Gibbs test: (-) grayish yellow. $\mathrm{UV}_{365 \mathrm{~nm}}$ fluorescence: dark purple. HR-MS: $\mathrm{M}^{+} 338.115, \mathrm{C}_{20} \mathrm{H}_{18} \mathrm{O}_{5}$ (requires 338.118). MS $m / z(\%): 339\left(\mathbf{M}^{+}+1,19\right), 338\left(\mathbf{M}^{+}, 80\right), 324(23), 323$ $\left(\mathrm{M}^{+}-15,100\right), 283\left(\mathrm{M}^{+}-55,37\right), 270\left(\mathrm{M}^{+}-68,48\right), 165$ 
(11), 141 (18), 118 (7.2). UV $\lambda_{\max }^{\mathrm{MeOH}} \mathrm{nm}: 266,335 \mathrm{sh}$; $+\mathrm{NaOMe}, 282,330 \mathrm{sh}$; $+\mathrm{AlCl}_{3}, 230 \mathrm{sh}, 241 \mathrm{sh}, 279,315 \mathrm{sh}$, 366 ; +NaOAc, 269, 283sh, 336.

Lupiwighteone triacetate (1a). Acetylation of 1 (2.6 mg) yielded $2.6 \mathrm{mg}$ of the triacetate (1a) as colorless plates. Gibbs test: (-) colorless. $\mathrm{UV}_{365 \mathrm{~nm}}$ fluorescence: white/ blue. MS $m / z(\%): 464\left(\mathrm{M}^{+}, 2.2\right), 423(22), 422\left(\mathrm{M}^{+}-42\right.$, $80), 380\left(\mathrm{M}^{+}-84,66\right), 379(63), 338\left(\mathrm{M}^{+}-126,100\right), 337$ (58), 323 (82), 283 (32), 270 (51), 165 (9.6), 118 (9.4), 43 (90). UV $\lambda_{\max }^{\mathrm{MeOH}} \mathrm{nm}: 249,309 .{ }^{1} \mathrm{H}-\mathrm{NMR} \delta_{\mathrm{TMS}}^{\text {acetone- } d_{6}}(100$ MHz): 1.68 and 1.84 (both $3 \mathrm{H}$, each br. s, $4^{\prime \prime}-\mathrm{H}_{3}$ and $5^{\prime \prime}$ $\left.\mathrm{H}_{3}\right), 2.28$ (3H, s, 4'-OAc), 2.30 (3H, s, 7-OAc), $2.38(3 \mathrm{H}, \mathrm{s}$, 5-OAc), 3.54 ( $2 \mathrm{H}$, br. d, $\left.J=7.1 \mathrm{~Hz}, 1^{\prime \prime}-\mathrm{H}_{2}\right), 5.19$ (1H, br. t, $\left.J=7.1 \mathrm{~Hz}, 2^{\prime \prime}-\mathrm{H}\right), 6.98(1 \mathrm{H}, \mathrm{s}, 6-\mathrm{H}), 7.18(2 \mathrm{H}$, br. d, $J=$ $8.7 \mathrm{~Hz}, 3^{\prime}-\mathrm{H}$ and $\left.5^{\prime}-\mathrm{H}\right), 7.60\left(2 \mathrm{H}\right.$, br. d, $J=8.7 \mathrm{~Hz}, 2^{\prime}-\mathrm{H}$ and $\left.6^{\prime}-\mathrm{H}\right), 8.40(1 \mathrm{H}, \mathrm{s}, 2-\mathrm{H})$.

2,3-Dehydrokievitone [BR-A, 2]. Pale yellow columns, $\mathrm{mp} 145 \sim 146^{\circ} \mathrm{C}$. Gibbs test: (+) rapid, blue/purple. $\mathrm{UV}_{365 \mathrm{~nm}}$ fluorescence: dark purple. HR-MS: $\mathrm{M}^{+}$354.109, $\mathrm{C}_{20} \mathrm{H}_{18} \mathrm{O}_{6}$ (requires 354.113). MS $m / z(\%): 355\left(\mathrm{M}^{+}+1\right.$, 12), $354\left(\mathrm{M}^{+}, 100\right), 339\left(\mathrm{M}^{+}-15,6.5\right), 311\left(\mathrm{M}^{+}-43,92\right)$, $299\left(\mathrm{M}^{+}-55,56\right), 165$ (20), 134 (4.8). UV $\lambda_{\max }^{\mathrm{MeOH}} \mathrm{nm}: 265$; +NaOMe, 282; $+\mathrm{AlCl}_{3}, 275,316,376$; + NaOAc, 279.

2,3-Dehydrokievitone tetraacetate (2a). Acetylation of $\mathbf{2}$ $(12.9 \mathrm{mg})$ yielded $11.7 \mathrm{mg}$ of the tetraacetate $(\mathbf{2 a})$ as colorless plates. Gibbs test: (-) colorless. $\mathrm{UV}_{365 \mathrm{~nm}}$ fluorescence: dark blue. MS $m / z(\%): 481\left(\mathrm{M}^{+}+1,11\right), 480\left(\mathrm{M}^{+}\right.$, 34), $438\left(\mathrm{M}^{+}-42,32\right), 420(10), 396\left(\mathrm{M}^{+}-84,29\right), 395$ (38), 383 (13), $354\left(\mathrm{M}^{+}-126,20\right), 353$ (40), 341 (24), 311 (37), 299 (29), 219 (16), 165 (15), 149 (18), 134 (8), 43 (100). UV $\lambda_{\max }^{\mathrm{MeOH}} \mathrm{nm}: 245,253 \mathrm{sh}, 309 .{ }^{1} \mathrm{H}-\mathrm{NMR} \delta_{\mathrm{TMS}}^{\text {acetone- } d_{6}}(100$ $\mathrm{MHz}$ ): 1.68 and 1.84 (both $3 \mathrm{H}$, each br. s, $4^{\prime \prime}-\mathrm{H}_{3}$ and $5^{\prime \prime}-$ $\left.\mathrm{H}_{3}\right), 2.11$ (3H, s, 2'-OAc), 2.27 (3H, s, 4'-OAc), $2.28(3 \mathrm{H}$, s, 5-OAc), 2.38 (3H, s, 7-OAc), $3.54(2 \mathrm{H}$, br. d, $J=7.1 \mathrm{~Hz}$, $\left.1^{\prime \prime}-\mathrm{H}_{2}\right), 5.19\left(1 \mathrm{H}\right.$, br. t, $\left.J=7.1 \mathrm{~Hz}, 2^{\prime \prime}-\mathrm{H}\right), 7.00(1 \mathrm{H}, \mathrm{s}, 6-$ H), $7.08\left(1 \mathrm{H}, \mathrm{d}, J=2.2 \mathrm{~Hz}, 3^{\prime}-\mathrm{H}\right), 7.09(1 \mathrm{H}, \mathrm{dd}, J=9.0$ and $\left.2.2 \mathrm{~Hz}, 5^{\prime}-\mathrm{H}\right), 7.43\left(1 \mathrm{H}, \mathrm{d}, J=9.0 \mathrm{~Hz}, 6^{\prime}-\mathrm{H}\right), 8.27(1 \mathrm{H}, \mathrm{s}$, 2-H).

2,3-Dehydrokievitone tetramethylether (2b). Methylation of $2(2.6 \mathrm{mg})$ yielded $1.5 \mathrm{mg}$ of the tetramethyl ether $(\mathbf{2 b})$ as pale yellow needles. Gibbs test: $(-)$ colorless. $U V_{365 \mathrm{~nm}}$ fluorescence: dark blue. $\mathrm{MS} m / z(\%): 411\left(\mathrm{M}^{+}+1,26\right), 410$ $\left(\mathrm{M}^{+}, 100\right), 409$ (19), 381 (13), 380 (9.2), $379\left(\mathrm{M}^{+}-31,39\right)$, 205 (9.9). UV $\lambda_{\max }^{\mathrm{MeOH}} \mathrm{nm}: 222 \mathrm{sh}, 250 \mathrm{sh}, 258,281 \mathrm{sh}, 320 \mathrm{sh}$. ${ }^{1} \mathrm{H}-\mathrm{NMR} \delta_{\text {TMS }}^{\text {acetone- } d_{6}}(100 \mathrm{MHz}): 1.68$ and 1.81 (both $3 \mathrm{H}$, each br. s, $4^{\prime \prime}-\mathrm{H}_{3}$ and $\left.5^{\prime \prime}-\mathrm{H}_{3}\right), 3.45(2 \mathrm{H}$, br. d, $J=7.3 \mathrm{~Hz}$, $1^{\prime \prime}-\mathrm{H}_{2}$ ), 3.57, 3.83, 3.89 and 4.01 (each $3 \mathrm{H}$, four s, $4 \times-$ $\mathrm{OMe}), 5.20\left(1 \mathrm{H}\right.$, br. t $\left.J=7.1 \mathrm{~Hz}, 2^{\prime \prime}-\mathrm{H}\right), 6.53(3 \mathrm{H}$, dd, $J=8.0$ and $\left.2.4 \mathrm{~Hz}, 5^{\prime}-\mathrm{H}\right), 6.60\left(1 \mathrm{H}, \mathrm{s}, J=2.4 \mathrm{~Hz}, 3^{\prime}-\mathrm{H}\right)$, $6.68(1 \mathrm{H}, \mathrm{s}, 6-\mathrm{H}), 7.16\left(1 \mathrm{H}\right.$, br. d, $\left.J=8.0 \mathrm{~Hz}, 6^{\prime}-\mathrm{H}\right), 7.89$ (1H, s, 2-H).

Cyclo-2,3-dehydrokievitone (2c). Acid-catalyzed cycliza- tion of the prenyl group of $2(2.0 \mathrm{mg})$ yielded $1.8 \mathrm{mg}$ of cyclo-2,3-dehydrokievitone (2c) as pale yellow needles, $\mathrm{mp}$ $203 \sim 205^{\circ} \mathrm{C}$. Gibbs test: $(+)$ rapid, blue/purple. $\mathrm{UV}_{365 \mathrm{~nm}}$ fluorescence: dark purple. MS $m / z(\%): 355\left(\mathrm{M}^{+}+1,7.2\right)$, $354\left(\mathrm{M}^{+}, 100\right), 311\left(\mathrm{M}^{+}-43,15\right), 299\left(\mathrm{M}^{+}-55,63\right), 165$ (40), 134 (24). UV $\lambda_{\text {max }}^{\mathrm{MeOH}} \mathrm{nm}: 267 ;+\mathrm{AlCl}_{3}, 278,317,376$; $+\mathrm{NaOAc}, 267 .{ }^{1} \mathrm{H}-\mathrm{NMR} \delta_{\mathrm{TMS}}^{\text {acetone- } d_{6}}(100 \mathrm{MHz}): 1.38(6 \mathrm{H}$, s, $5^{\prime \prime}-\mathrm{H}_{3}$ and $\left.6^{\prime \prime}-\mathrm{H}_{3}\right), 1.92\left(2 \mathrm{H}, \mathrm{t}, J=6.7 \mathrm{~Hz}, 3^{\prime \prime}-\mathrm{H}_{2}\right), 2.83$ $\left(2 \mathrm{H}, \mathrm{t}, J=6.7 \mathrm{~Hz}, 4^{\prime \prime}-\mathrm{H}_{2}\right), 6.18(1 \mathrm{H}, \mathrm{s}, 6-\mathrm{H}), 6.44(1 \mathrm{H}, \mathrm{dd}$, $J=8.5$ and $\left.2.2 \mathrm{~Hz}, 5^{\prime}-\mathrm{H}\right), 6.49\left(1 \mathrm{H}\right.$, incomplete d, $\left.3^{\prime}-\mathrm{H}\right)$, $7.14\left(1 \mathrm{H}, \mathrm{d}, J=8.5 \mathrm{~Hz}, 6^{\prime}-\mathrm{H}\right), 8.27(1 \mathrm{H}, \mathrm{s}, 2-\mathrm{H}), 12.51(1 \mathrm{H}$, s, 5-OH).

Luteone hydrate [BR-C, 3]. Pale yellow glassy solid. Gibbs test: $(+)$ rapid, blue/purple. $\mathrm{UV}_{365 \mathrm{~nm}}$ fluorescence: dark purple. HR-MS: $\mathrm{M}^{+} 372.120, \mathrm{C}_{20} \mathrm{H}_{20} \mathrm{O}_{7}$ (requires 372.121). MS $m / z(\%): 372\left(\mathrm{M}^{+}, 11\right), 354\left(\mathrm{M}^{+}-18,41\right)$, $311\left(\mathrm{M}^{+}-61,31\right), 299\left(\mathrm{M}^{+}-73,100\right), 298$ (25), $165(31)$, 134 (4.2). UV $\lambda_{\max }^{\mathrm{MeOH}} \mathrm{nm}: 256 \mathrm{sh}, 266$; + NaOMe, 278; $+\mathrm{AlCl}_{3}, 218 \mathrm{sh}, 274,315$; + NaOAc, 272, 340.

Lupiwighteone hydrate [BR-E, 4]. Colorless columns, $\mathrm{mp}$ $244 \sim 246^{\circ} \mathrm{C}$. Gibbs test: (-) grayish yellow. $\mathrm{UV}_{365 \mathrm{~nm}}$ fluorescence: dark purple. HR-MS: $\mathrm{M}^{+} 356.122, \mathrm{C}_{20} \mathrm{H}_{20} \mathrm{O}_{6}$ (requires 356.126). $\mathrm{MS} m / z(\%): 357\left(\mathrm{M}^{+}+1,5.8\right), 356$ $\left(\mathrm{M}^{+}, 24\right), 338\left(\mathrm{M}^{+}-18,24\right), 323\left(\mathrm{M}^{+}-33,42\right), 284(19)$, 283 (100), 270 (20), 165 (19), 141 (12), 118 (6.8). UV $\lambda_{\max }^{\mathrm{MeOH}} \mathrm{nm}: 266,335 ;+\mathrm{AlCl}_{3}, 230 \mathrm{sh}, 278,318,384$; $+\mathrm{NaOAc}, 269,280 \mathrm{sh}, 333$

2,3-Dehydrokievitone hydrate [BR-D, 5]. Yellow needles, $\mathrm{mp} 134 \sim 136^{\circ} \mathrm{C}$. Gibbs test: $(+)$ rapid, blue/purple. $\mathrm{UV}_{365 \mathrm{~nm}}$ fluorescence: dark purple. HR-MS: $\mathbf{M}^{+} 372.118$, $\mathrm{C}_{20} \mathrm{H}_{20} \mathrm{O}_{7}$ (requires 372.121). $\mathrm{MS} m / z(\%)$ : $372\left(\mathrm{M}^{+}, 24\right)$, $354\left(\mathrm{M}^{+}-18,39\right), 323\left(\mathrm{M}^{+}-61,45\right), 299\left(\mathrm{M}^{+}-73,100\right)$, 298 (60), 165 (55), 134 (28). UV $\lambda_{\max }^{\mathrm{MeOH}} \mathrm{nm}: 255 \mathrm{sh}, 265$; $+\mathrm{AlCl}_{3}$; 274, 315, 376; +NaOAc; 266sh, 268 272br, $295 \mathrm{sh}, 337$.

Hydroxywighteone [BR-G, 6]. Pale yellow columns, mp $258 \sim 260^{\circ} \mathrm{C}$. Gibbs test: $(+)$ slow, blue $/$ green. $\mathrm{UV}_{365 \mathrm{~nm}}$ fluorescence: dark purple. $\mathrm{HR}-\mathrm{MS}: \mathrm{M}^{+} 354.115, \mathrm{C}_{20} \mathrm{H}_{18} \mathrm{O}_{6}$ (requires 354.110). MS m/z (\%): $354\left(\mathrm{M}^{+}, 4.5\right), 336$ $\left(\mathrm{M}^{+}-18,36\right), 322(22), 321\left(\mathrm{M}^{+}-33,100\right), 295\left(\mathrm{M}^{+}-59\right.$, 21), $284\left(\mathrm{M}^{+}-71,63\right), 270$ (7.0), 149 (10), 118 (12). UV $\lambda_{\max }^{\mathrm{MeOH}} \mathrm{nm}: 215 \mathrm{sh}, 267$; $+\mathrm{AlCl}_{3}, 242 \mathrm{sh}, 271,283 \mathrm{br} \mathrm{sh}$, 320sh; + NaOAc, 270, 335.

Hydroxyparvisoflavone $A$ [BR-H, 7]. Yellow plates, mp $172 \sim 174^{\circ} \mathrm{C}$. Gibbs test: $(+)$ rapid, blue/purple. $\mathrm{UV}_{365 \mathrm{~nm}}$ fluorescence: dark purple. $\mathrm{HR}-\mathrm{MS}: \mathrm{M}^{+} 368.087, \mathrm{C}_{20} \mathrm{H}_{16} \mathrm{O}_{7}$ (requires 368.090). MS $m / z(\%): 368\left(\mathrm{M}^{+}, 21\right), 338(24)$, $337\left(\mathrm{M}^{+}-31,100\right), 319\left(\mathrm{M}^{+}-49,14\right), 203$ (82), 176 (14), 134 (13). UV $\lambda_{\max }^{\mathrm{MeOH}} \mathrm{nm}: 267 \sim 271 \mathrm{br} ;+\mathrm{AlCl}_{3}, 225 \mathrm{sh}$, $279 \sim 285$ br; +NaOAc, $269 \sim 272$ br.

Lupilutin [BR-F, 8]. Colorless columns, mp $284 \sim 286^{\circ} \mathrm{C}$. 
Gibbs test: ( - ) colorless. $\mathrm{UV}_{365 \mathrm{~nm}}$ fluorescence: brownish yellow. HR-MS: $\mathrm{M}^{+} 370.105, \mathrm{C}_{20} \mathrm{H}_{18} \mathrm{O}_{7}$ (requires 370.105). MS $m / z(\%): 370\left(\mathrm{M}^{+}, 16\right), 352\left(\mathrm{M}^{+}-18,40\right)$, $337\left(\mathrm{M}^{+}-33,30\right) ; 298(19), 297\left(\mathrm{M}^{+}-73,100\right), 284$ (14), $176(10), 148$ (7.8). IR $v_{\max }^{\mathrm{KBr}} \mathrm{cm}^{-1}: 3400,1650,1570,1380$, 1080, 1010. UV data are shown in Table III.

Acknowledgments. We wish to thank Dr. J. L. Ingham for his invaluable advice, Miss Y. Hatakeyama for determining the ${ }^{1} \mathrm{H}-\mathrm{NMR}$ spectra, and Miss Y. Atsuta and Mr. K. Watanabe for MS analyses. Financial support (to J. M.) by a Grant-in-Aid for Scientific Research (No. 59430021) from the Ministry of Education, Science and Culture of Japan is also gratefully acknowledged.

\section{REFERENCES}

1) J. L. Ingham, S. Tahara and J. B. Harborne, $Z$. Naturforsch., 38C, 194 (1983).

2) S. Tahara, J. L. Ingham, S. Nakahara, J. Mizutani and J. B. Harborne, Phytochemistry, 23, 1889 (1984).

3) S. Tahara, J. L. Ingham and J. Mizutani, Agric. Biol. Chem., 49, 1775 (1985).
4) T. J. Mabry, K. R. Markham and M. B. Thomas, "The Systematic Identification of Flavonoids," Springer, Berlin, 1970, p. 169.

5) J. L. Ingham, "Phytoalexins," ed. by J. A. Bailey and J. W. Mansfield, Blackie, Glasgow, 1982, p. 21.

6) K. R. Markham and T. J. Mabry, "The Flavonoids," ed. by J. B. Harborne, T. J. Mabry and H. Mabry, Chapman and Hall, London, 1975, p. 45.

7) M. D. Woodward, Phytochemistry, 18, 2007 (1979).

8) S. Tahara, S. Nakahara, J. Mizutani and J. L. Ingham, Agric. Biol. Chem., 48, 1471 (1984).

9) S. Tahara, S. Nakahara, J. L. Ingham and J. Mizutani, Nippon Nôgeikagaku Kaishi, 59, 1039 (1985).

10) M. Darbarwar, V. Sundaramurthy and N. V. Subba Rao, J. Scient. Int. Res. (India), 35, 297 (1976).

11) F. E. King, T. J. King and L. C. Manning, J. Chem. Soc., 1957, 563.

12) R. M. V. Assumpção and O. R. Gottlieb, Phytochemistry, 12, 1188 (1973).

13) S. Tahara, Y. Hashidoko, J. L. Ingham and J. Mizutani, Agric. Biol. Chem., 50, 1809 (1986). 